\title{
Facile synthesis of fluorescent $A B A$ type amphiphilic triblock copolymers via RAFT polymerization and their aggregation behavior in a selective solvent
}

\author{
Junwei Fu, Zhenping Cheng, Nianchen Zhou, Jian Zhu, Wei Zhang and Xiulin Zhu* \\ *Key Lab. of Organic Synthesis of Jiangsu Province, College of Chemistry, Chemical \\ Engineering and Materials Science, Soochow University, Suzhou 215123, China; fax: \\ (+86) 5126511 2796; e-mail: xlzhu@suda.edu.cn
}

(Received: 3 April, 2008; published: 16 February, 2009)

\begin{abstract}
Well-defined naphthalene end-capped poly(styrene)-block-poly( $\mathrm{N}$ isopropyl-acrylamide)-block-poly(styrene) (PS-b-PNIPAM- $b$-PS) amphiphilic triblock copolymers with different molecular weights and block copolymer compositions were successfully prepared via consecutive reversible additionfragmentation chain transfer (RAFT) polymerizations using a novel RAFT reagent, S,S'-bis(1-naphthylmethyl) trithiocarbonate (BNTTC). The aggregation behaviour of the prepared PS- $b$-PNIPAM- $b$-PS in water/DMF mixture was studied by transmission electron microscopy (TEM). The effect of the copolymer concentration, PNIPAM block length and the irradiation of UV-light on the sizes and morphologies of micelles were also investigated.
\end{abstract}

\section{Introduction}

Amphiphilic copolymers have received considerable interest in recent years due to their self-assembly properties and their biomedical applications [1-4]. The unique amphiphilic character of these copolymers enables them to self-assemble into versatile micelles with different morphologies including spherical micelles, wormlike micelles, rod-like micelles, lamellae, vesicles, toroidal (ring-like) or larger aggregates [5-7]. The aggregates from amphiphilic copolymers are thermodynamically and kinetically more stable, so they are of interest for many potential applications. Such micelles can be applied in drug delivery, gene therapy, and phase transfer catalysis, as templates for the fabrication of nanostructured hybrids and nanoparticles, and as reaction media for biocatalysts in liquid phase [8-12].

Poly(N-isopropylacrylamide) (PNIPAM) is one of the well-known hydrophilic polymers and can be used to prepare amphiphilic materials. These amphiphilic block copolymers with the PNIPAM as hydrophilic block, such as PNIPAM- $b$-PS [13], PNIPAM- $b$-PS- $b$-PNIPAM [14], PBE- $b$-PNIPAM [15], PNIPAM- $b$-PAA [16], PLA- $b-$ PNIPAM- $b$-PLA [17], and PEG- $b$-PNIPAM- $b$-PS [18], can self-assemble into micelles in water or selective solution, which has the potential to be used as nano-reactors, drug delivery and site-specific gene vehicles, or templates for preparing inorganic mesoporous materials.

Block copolymers have been synthesized with a variety of different synthetic strategies. There are several possible methods to prepare amphiphilic block copolymers. The most common ways are living anionic, cationic, ring-opening, and radical polymerizations that can produce well-defined block copolymers with 
controlled molecular weights and narrow polydispersities (PDIs) [19-23]. Recently, "living"/controlled radical polymerization techniques have been well researched. The main "living"/controlled radical polymerization techniques are nitroxide-mediated radical polymerization (NMP), atom transfer radical polymerization (ATRP), and reversible addition-fragmentation chain transfer (RAFT) polymerization [24-28]. However, RAFT polymerization performs well as a promising controlled free-radical polymerization technique because of its versatility and simplicity, and the polymer is free from the contamination of metal catalysts. Most importantly, it is compatible with almost all conventional free-radical polymerization monomers, including NIPAM [2931]. Trithiocarbonate, which can be synthesized with two good homolytic leaving groups, is an effective RAFT agent to be applied to prepare telechelic ABA triblock copolymers [32, 33]. More interestingly, the UV light-responsive property of trithiocarbonate broadens its applications in some aspects [34, 35].

In this work, the fluorescent ABA type amphiphilic triblock copolymers (PS- $b$ PNIPAM- $b$-PS) with controlled molecular weights and narrower molecular weight distributions were facilely synthesized via RAFT polymerization using S,S'-bis(1naphthylmethyl) trithiocarbonate (BNTTC) as a RAFT agent. The fluorescence of the polymers were also investigated. The prepared PS- $b$-PNIPAM- $b$-PS was used to form micelles by addition of water to copolymer/DMF solution. The sizes and morphologies of micelles were studied by transmission electron microscopy (TEM) technique. Furthermore, we studied the effect of the copolymer concentration, the hydrophilic PNIPAM block length and content, and UV-light irradiation on sizes and morphologies of micelles. The structure of BNTTC is shown in scheme 1.

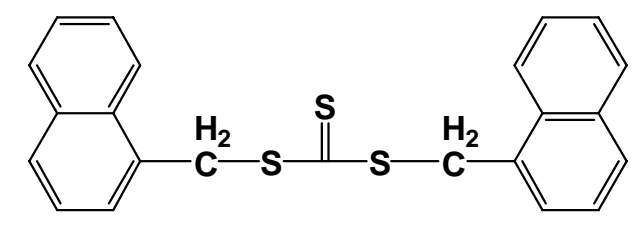

BNTTC

Scheme 1. The structure of S,S'-bis(1-naphthylmethyl) trithiocarbonate (BNTTC)

\section{Results and discussion}

Preparation of Fluorescent ABA Type Amphiphilic Triblock Copolymers PS-bPNIPAM- $b-P S$ via RAFT Polymerizations

A series of block copolymers of PS- $b$-PNIPAM- $b$-PS with different molecular weights and block compositions were synthesized via consecutive RAFT polymerizations of styrene and NIPAM using BNTTC as the RAFT agent. The results are shown in Table 1, in which, well-defined PS and PS- $b$-PNIPAM- $b$-PS with controlled molecular weight and narrow polydispersity (PDI < 1.13) were obtained by the RAFT polymerizations using BNTTC as a very effective RAFT agent. The GPC was used to follow the polymerization (Fig. 1). There was a peak shift from the macro-RAFT agent to the chain-extended block copolymer, and the molecular weight increased from $4100 \mathrm{~g} / \mathrm{mol}$ to $5200 \mathrm{~g} / \mathrm{mol}$, indicating that PNIPAM was inserted into the middle of the PS chain. Further verification of the molecular structure of the PS- $b$-PNIPAM- $b$-PS was established by ${ }^{1} \mathrm{H}$ NMR (Fig. 2). As compared with PS, the chemical shifts at 3.9 ppm and $1.1 \mathrm{ppm}$ (Fig. 2(b)) were assigned to the protons of methine and methyl 
groups in the PNIPAM, respectively, verifying the formation of the amphiphilic triblock copolymer.

Tab. 1. Molecular weights and polydispersities of the maro-RAFT agents (PS) and corresponding block copolymers (PS- $b-P N I P A M-b-P S)$.

\begin{tabular}{cccccc}
\hline${ }^{\mathrm{a}}$ samples & ${ }^{\mathrm{b}} \mathrm{S}-\mathrm{N}-\mathrm{S}$ & ${ }^{\mathrm{c}} M_{\mathrm{n}, \mathrm{GPC}}$ & ${ }^{\mathrm{c}} P D I$ & ${ }^{\mathrm{d}} M_{\mathrm{n}, \text { th }}$ & $M_{\mathrm{n}, \mathrm{NMR}}$ \\
\hline PS1 & $22-0-22$ & 4100 & 1.07 & 4300 & $4400^{\mathrm{e}}$ \\
PS2 & $43-0-43$ & 8800 & 1.08 & 8900 & $8900^{\mathrm{e}}$ \\
CP1 & $22-12-22$ & 5200 & 1.11 & 5600 & $5800^{\mathrm{f}}$ \\
CP2 & $22-5-22$ & 4400 & 1.08 & 4900 & $5000^{\mathrm{f}}$ \\
CP3 & $43-5-43$ & 8900 & 1.13 & 9400 & $9500^{\mathrm{f}}$ \\
\hline
\end{tabular}

${ }^{a}$ Polymerization conditions for PS: [St]:[BNTTC]:[AIBN] $=300: 6: 1$, temperature $=70{ }^{\circ} \mathrm{C}$ in bulk. Copolymerization conditions for NIPAM: [NIPAM]:[Macro-RAFT agent]:[AIBN] = 240:6:1, temperature = $70^{\circ} \mathrm{C}, 1.5 \mathrm{ml}$ THF in each ampoule.

${ }^{b} \mathrm{~S}$ means the degree of polymerization of PS and $\mathrm{N}$ means the degree of polymerization of PNIPAM.

${ }^{\mathrm{C}}$ The number-average molecular weights and polydispersities of the polymers measured by GPC.

${ }^{\mathrm{d}}$ The number-average molecular weights calculated from the molar ratios of monomer to RAFT agent.

${ }^{\mathrm{e}}$ The molecular weight of PS was calculated from

$M_{P S, N M R}=\left(\frac{I_{6.28 \sim 7.50}}{5} / \frac{I_{7.56 \sim 7.74}}{4}\right) \times M W_{S t}+M_{B N T T C}$

where $I_{6.28 \sim 7.50}$ is the integral of the signals at $6.28-7.50 \mathrm{ppm}$ and $I_{7.56 \sim 7.74}$ is the integral of the signals at 7.56-7.74 ppm.

${ }^{\mathrm{f}}$ The molecular weight of copolymer was calculated from $M_{n, N M R}=\left(\frac{I_{3.80 \sim 4.20}}{1} / \frac{I_{6.28 \sim 7.50}}{5}\right) \times M W_{N I P A M} \times M_{P S, N M R} / M W_{S t}+M_{B N T T C}$

where $I_{3.80 \sim 4.20}$ is the integral of the signals at $I_{3.80 \sim 4.20}$ is the integral of the signals at 3.80-4.20 ppm and $I_{6.28 \sim 7.50}$ is the integral of the signals at $6.28-7.50 \mathrm{ppm}$.

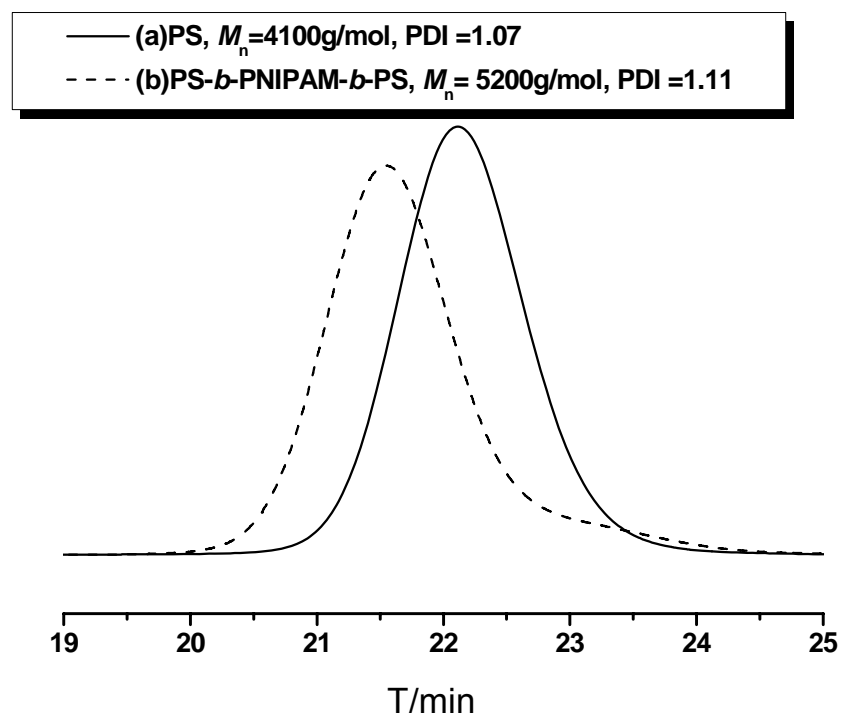

Fig. 1. GPC curves for triblock copolymer, (a) PS $\left(M_{\mathrm{n}, \mathrm{GPC}}=4100 \mathrm{~g} / \mathrm{mol}, \mathrm{PDI}=1.07\right)$; (b) $\mathrm{PS}_{22}-b-P N I P A M_{12}-b-\mathrm{PS}_{22}\left(M_{\mathrm{n}, \mathrm{GPC}}=5200 \mathrm{~g} / \mathrm{mol}, \mathrm{PDI}=1.11\right)$. 
The chemical shifts from 7.5 to $8.0 \mathrm{ppm}$ of the copolymer corresponded to naphthalene group of the macro-RAFT agent. The chemical structure of the formed triblock copolymer was also confirmed by FTIR spectra as shown in Figure 3. The characteristic absorption bands at $1652 \mathrm{~cm}^{-1}$ (C=O stretching vibration of NIPAM) and $3323 \mathrm{~cm}^{-1}(\mathrm{~N}-\mathrm{H}$ stretching vibration of NIPAM) appeared in the FTIR spectrum (Fig. 3(b)) after block copolymerization with NIPAM.

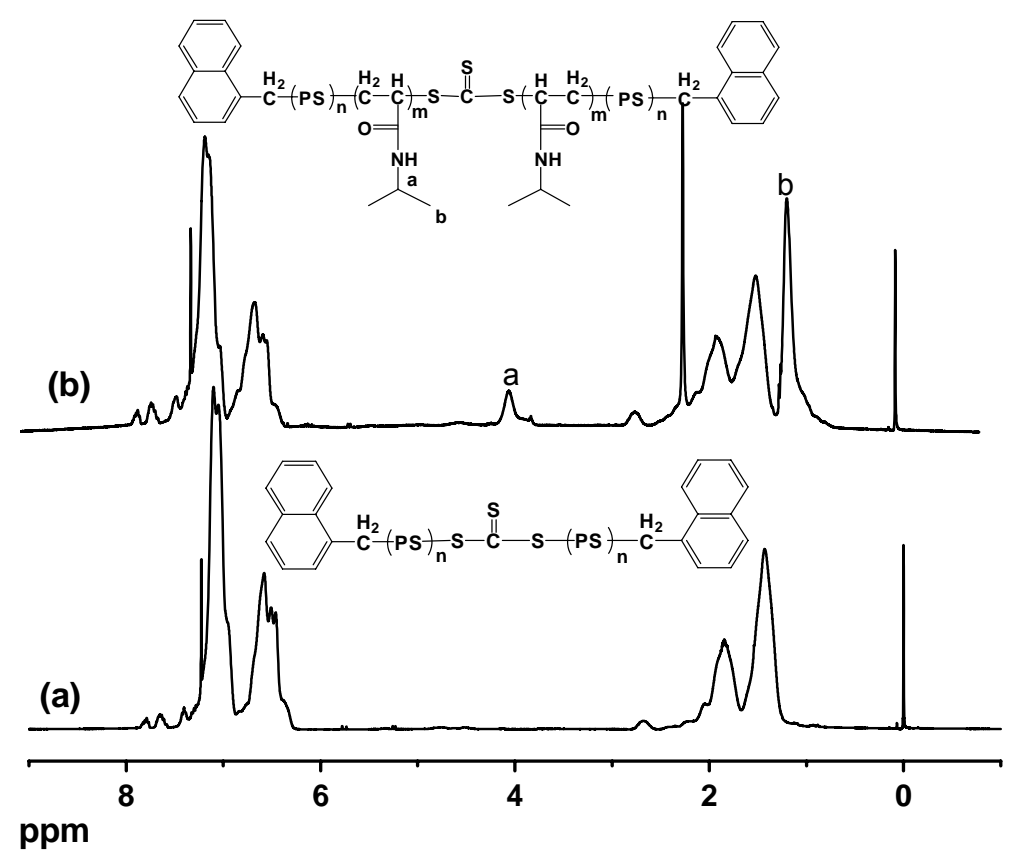

Fig. 2. ${ }^{1} \mathrm{H}$ NMR spectra of PS and PS- $b$-PNIPAM- $b-P S$, (a) PS $\left(M_{\mathrm{n}, \mathrm{GPC}}=4100 \mathrm{~g} / \mathrm{mol}\right.$, $\mathrm{PDI}=1.07) ;(\mathrm{b}) \mathrm{PS}_{22}-b-\mathrm{PNIPAM}_{12}-b-\mathrm{PS}_{22}\left(M_{\mathrm{n}, \mathrm{GPC}}=5200 \mathrm{~g} / \mathrm{mol}, \mathrm{PDI}=1.11\right)$.

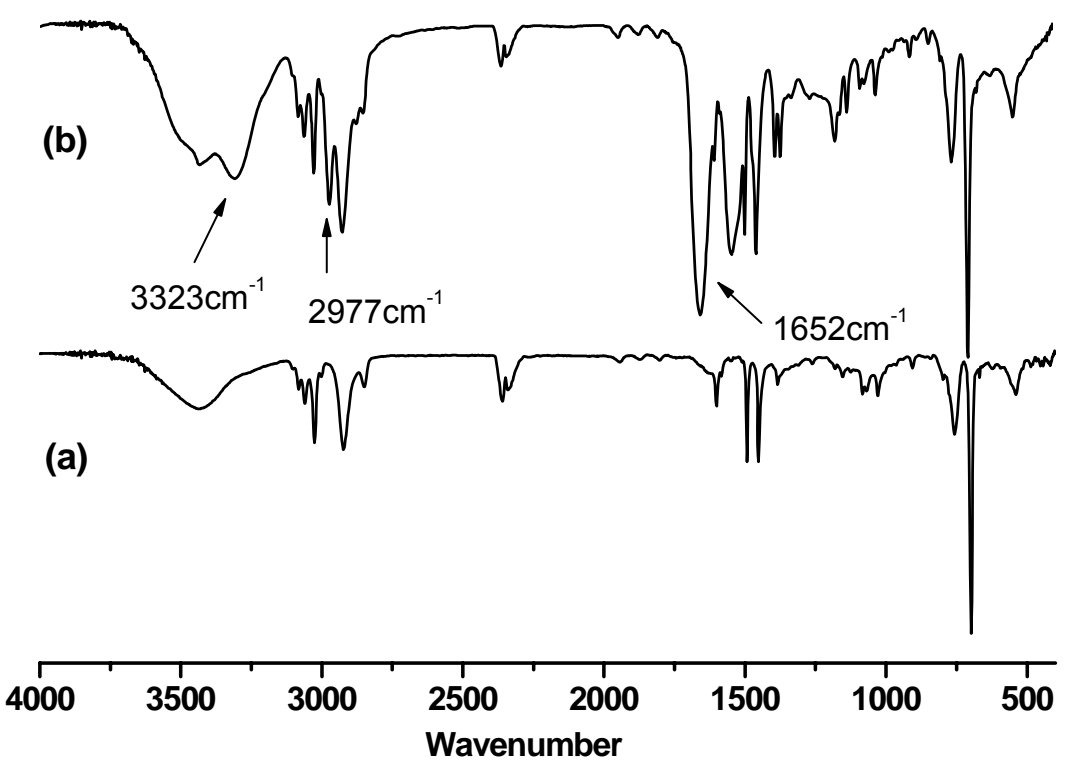

Fig. 3. IR spectra of PS and PS- $b$-PNIPAM- $b-P S$, (a) $P S\left(M_{\mathrm{n}, \mathrm{GPC}}=4100 \mathrm{~g} / \mathrm{mol}, \mathrm{PDI}=\right.$ 1.07); (b) $\mathrm{PS}_{22}-b-\mathrm{PNIPAM}_{12}-b-\mathrm{PS}_{22}\left(M_{\mathrm{n}, \mathrm{GPC}}=5200 \mathrm{~g} / \mathrm{mol}, \mathrm{PDI}=1.11\right)$. 
Fluorescence Property of Macro-RAFT Agent and Amphiphilic Triblock Copolymers End-Capped with Naphthalene

A Naphthalene group is a rigid conjugated molecule with strong fluorescence. According to the mechanism of RAFT polymerization, the functional group of the RAFT agent would exist at the end of the obtained PS and PS- $b$-PNIPAM- $b-P S$, which was confirmed by the ${ }^{1} \mathrm{H}$ NMR spectra (Figure 2). Therefore, we investigated the fluorescence of the macro-RAFT agent and the corresponding triblock copolymer in THF. The fluorescence spectra are shown in Figure 4. The characteristic absorption peak of naphthalene around $345 \mathrm{~nm}$ could be observed in THF at room temperature with excitation wavelength $\lambda_{\mathrm{ex}}=298 \mathrm{~nm}$ and the fluorescence intensity of the triblock copolymer was stronger than that of the macro-RAFT agent under the same concentration of naphthalene group, as expected by the documents reported previously [35, 36]. Therefore, the obtained ABA type amphiphilic triblock copolymer was additionally endowed with fluorescence, which would be beneficial for the potential application of these copolymers as fluorescence-labeled micelles [37].

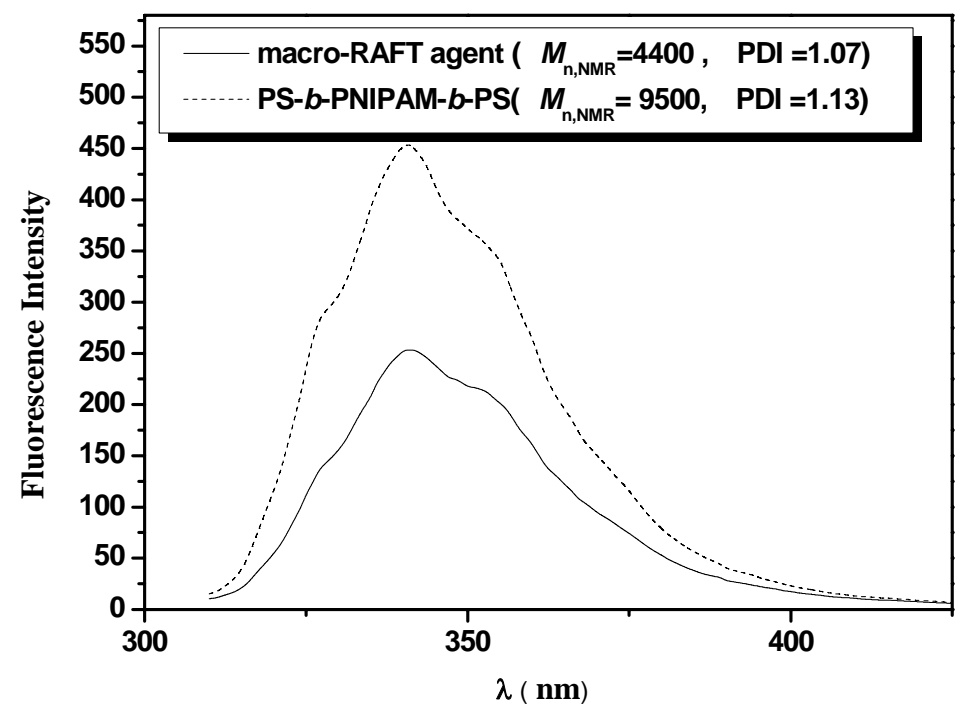

Fig. 4. Fluorescence spectra of the macro-RAFT agent and the corresponding triblock copolymer in THF at room temperature, and the concentrations of naphthalene moiety is $5.00 \times 10^{-5} \mathrm{M}, \lambda_{\mathrm{ex}}=298 \mathrm{~nm}$.

\section{Micellization of the Obtained PS- $b-P N I P A M-b-P S$}

The amphiphilic copolymers are able to form micelles [38, 39] easily by addition of water to polymer/DMF solution, and several factors can affect the sizes and morphologies of the formed micelles [40]. In this section, we investigated the formation of the obtained PS- $b$-PNIPAM- $b$-PS aggregates with different copolymer concentrations, and different hydrophilic PNIPAM block lengths and contents, by TEM. Three samples were used: CP1, CP2 and CP3 as shown in Table 1. The CP1 and CP2 had the same PS block length but different PNIPAM block lengths. In contrast, the CP2 and CP3 had the same PNIPAM block length but different PS block lengths. And the content of PNIPAM blocks decreased gradually in the order: $\mathrm{CP} 1>\mathrm{CP} 2>\mathrm{CP} 3$. Figure 5 shows the aggregates of CP1 $\left(\mathrm{PS}_{22}-b-\mathrm{PNIPAM}_{12}-b-\mathrm{PS}_{22}\right)$, made by addition of $5.5 \mathrm{wt} \%$ water to copolymer/DMF solution with different 
copolymer concentrations. As expected, the micelles formed under these conditions were almost spherical and the size depended on the CP1 concentration. The average diameter of spherical micelles, which was measured from the TEM image directly, increased gradually from $1.7 \mu \mathrm{m}$ (Figure 5a) for $1 \mathrm{wt} \%$ concentration, to 2.4 $\mu \mathrm{m}$ (Figure $5 \mathrm{~b}$ ) for $3 \mathrm{wt} \%$ concentration and $6.8 \mu \mathrm{m}$ (Figure $5 \mathrm{c}$ ) for $6 \mathrm{wt} \%$ concentration. These morphological changes can be ascribed to the fact that the aggregation number of the micelles and therefore the micelle core diameter increases as a function of the polymer concentration [40]. When the concentration increases, the distance between the micelles decreases and the coalescence of insufficiently stabilized small micelles happens [41]. A few short-rodlike micelles were formed as shown in Figure $5 b$ and $5 c$ which resulted from adhesive micelle collisions possibly when the copolymer concentration increased [40]. Figure 6 shows the TEM images of the self-assembled micelles of CP1, CP2 and CP3 which were made by the same method as described above with the same concentration of copolymer (1 wt \%). It could be found that the aggregates show an obvious morphological transition from sphere to bent cylinder with reduction in the hydrophilic PNIPAM content. With decreasing hydrophilic block length, the repulsive interactions between the coronal block chains decreased; thus, more chains aggregated, leading to larger aggregates like cylindrical micelles with a decreased core diameter [42].

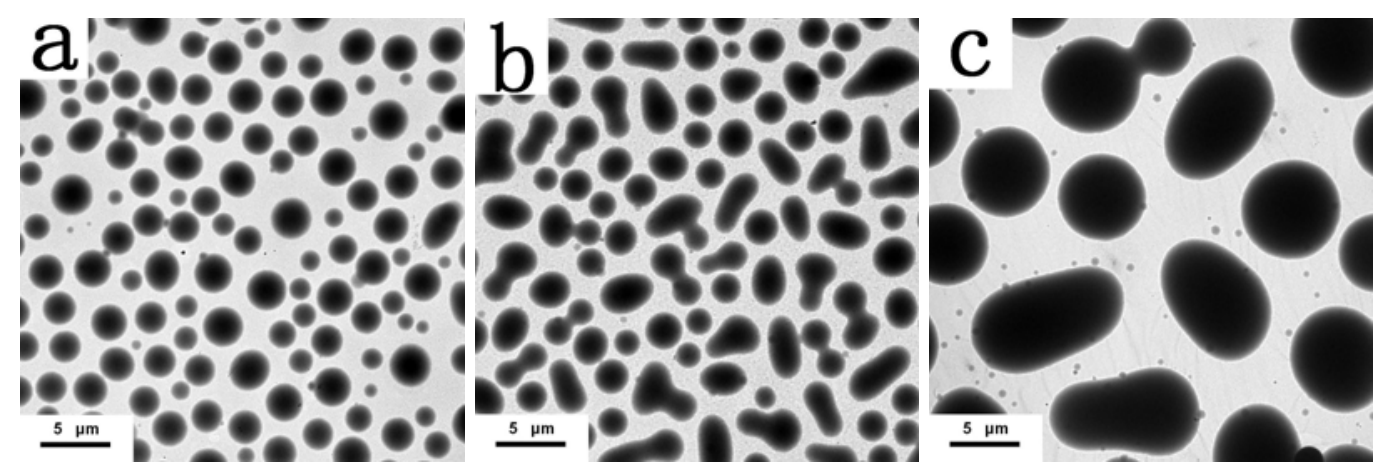

Fig. 5. TEM images of $\mathrm{PS}_{22}-b-\mathrm{PNIPAM}_{12}-b-\mathrm{PS}_{22}$ (CP1) aggregates obtained by addition of water to copolymer/DMF solution with different copolymer concentrations. Key: $1.0(\mathrm{a}), 3.0$ (b), and 6.0 wt \% (c).
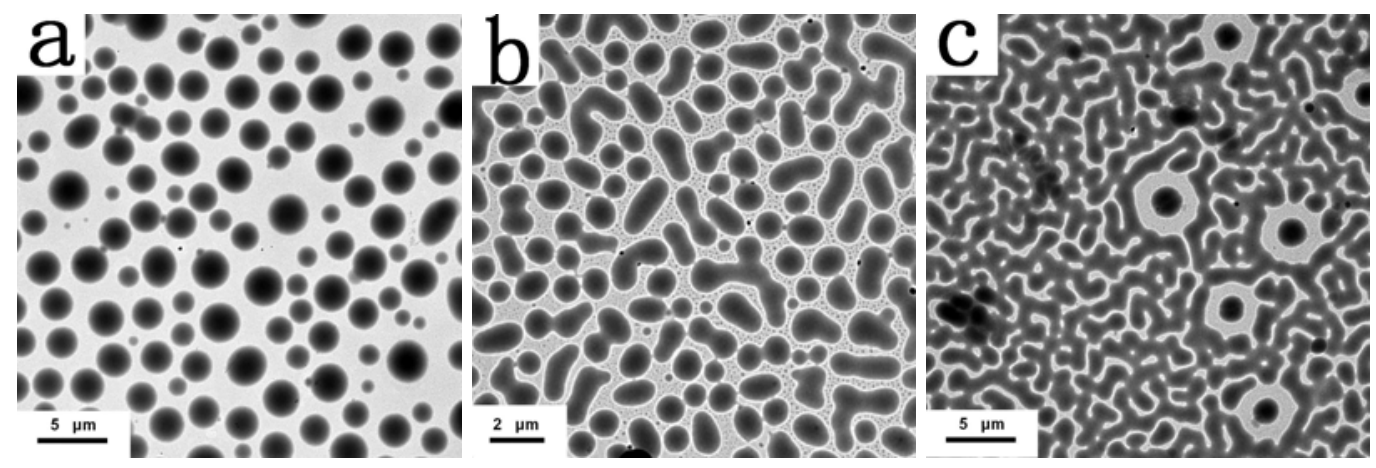

Fig. 6. TEM images of PS- $b$-PNIPAM- $b$-PS [CP1 (a), CP2 (b), CP3 (c)] aggregates with the same concentration of copolymer (1 wt \%). CP1 $=\mathrm{PS}_{22}-b-\mathrm{PNIPAM}_{12}-b-\mathrm{PS}_{22}$; CP2 $=$ PS $_{22}-b-$ PNIPAM $_{5}-b-\mathrm{PS}_{22} ; \mathrm{CP} 3=\mathrm{PS}_{43}-b-\mathrm{PNIPAM}_{5}-b-\mathrm{PS}_{43}$

According to the mechanism of RAFT polymerization, trithiocarbonate would exist in the middle of the triblock copolymer chain. As a result, the surface of the micelles 
obtained by addition of water to copolymer/DMF solution contains many UV lightresponsive trithiocarbonate groups [as shown in Fig. 7]. In this section, effect of UVlight irradiation on sizes and morphologies of micelles, which had rarely been reported before, was studied in relation to the fragmentation of UV light-responsive trithiocarbonate on the surface of micelles. The aggregates of $\mathrm{PS}_{43}-b-\mathrm{PNIPAM}_{5}-b-$ $\mathrm{PS}_{43}$ (CP3) obtained by addition of water to copolymer/DMF solution with $1.0 \mathrm{wt} \%$ copolymer concentration were irradiated by UV-light lamp $(380 \mathrm{~nm})$ for 4 hour with vigorous stirring. Figure 8 shows the TEM images of CP3 aggregates before (a) and after (b) irradiation by UV-light lamp. It is very interesting that there was a morphological transition from bent cylinder to sphere and the average size of spherical micelles decreased. This is attributed to the fragmentation of the trithiocarbonate groups in the middle of the triblock copolymer (CP3), which resulted in that the triblock copolymer PS- $b$-PNIPAM- $b$-PS transferred into diblock copolymer PS- $b$-PNIPAM. The plausible process for the micelle formation is demonstrated in Figure 9.

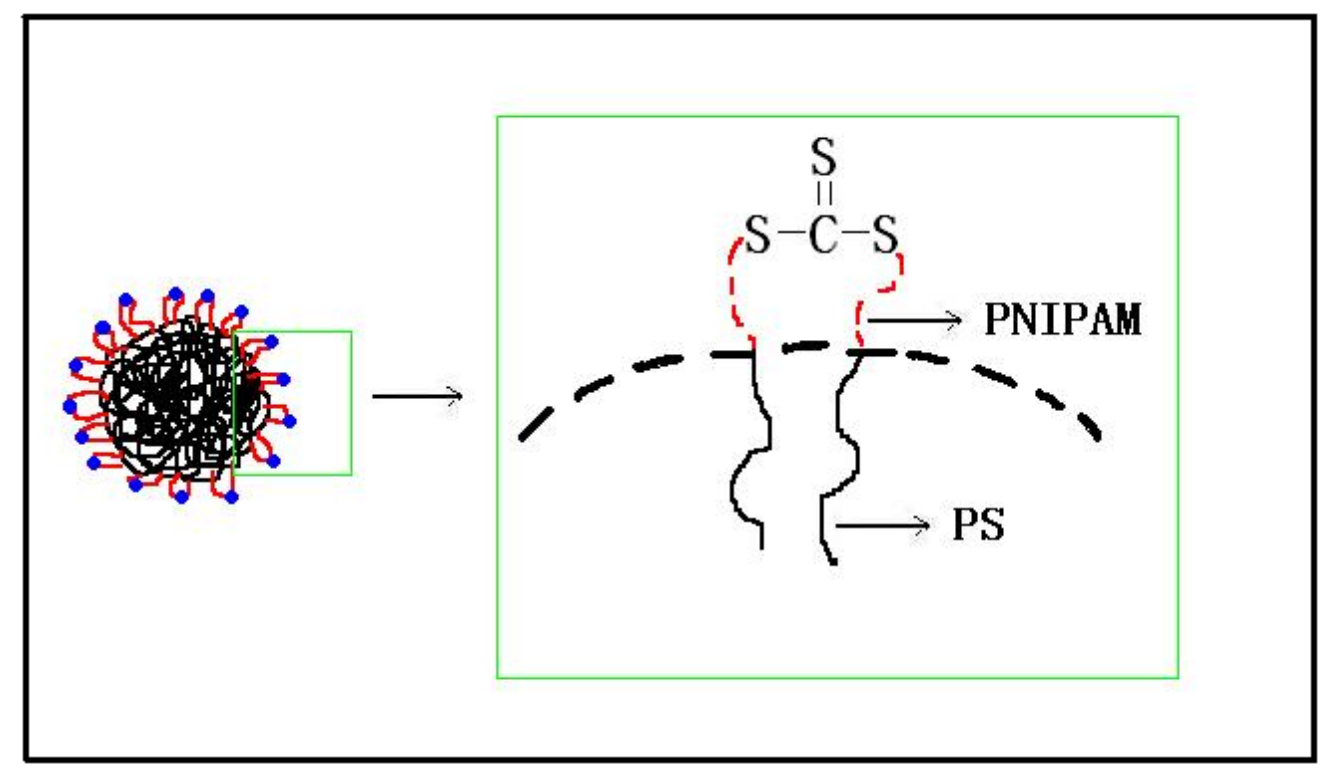

Fig. 7. Schematic illustration of chain conformation of PS- $b-P N I P A M-b-P S$ aggregates in DMF/water solution.



Fig. 8. TEM images of $\mathrm{PS}_{43}-b-\mathrm{PNIPAM}_{5}-b-\mathrm{PS}_{43}$ (CP3) aggregates before (a) and after (b) irradiation by UV-light $(\lambda=380 \mathrm{~nm})$ for $4 \mathrm{~h}$. 


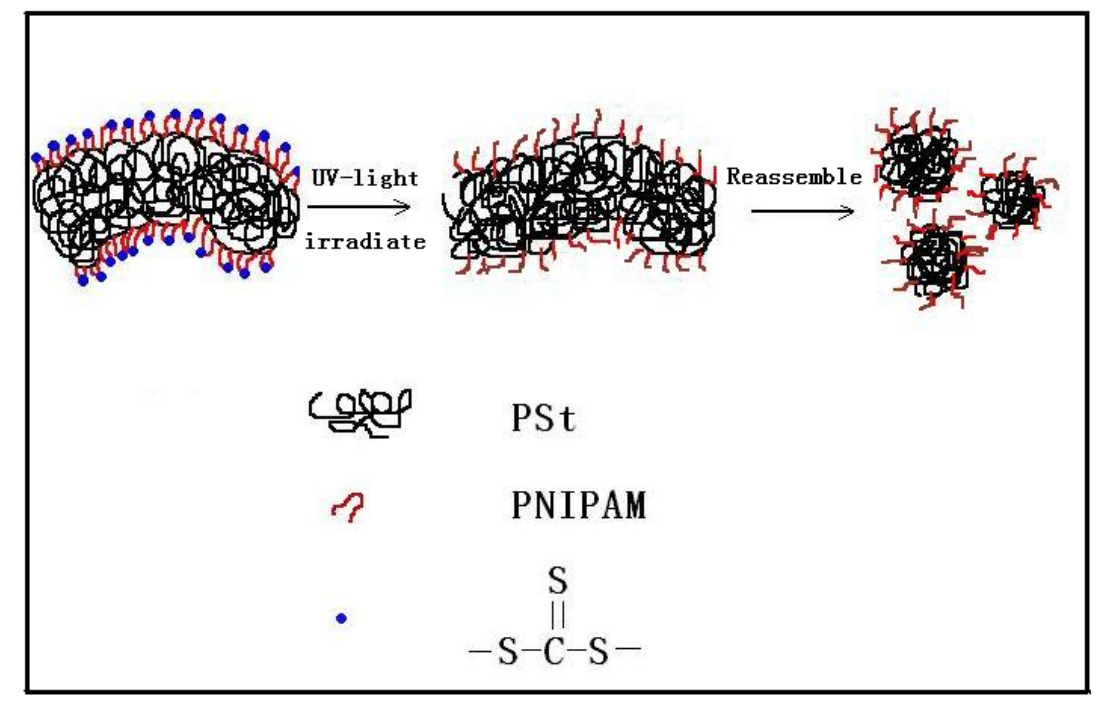

Fig. 9. Schematic representative morphological change of the copolymer micelles by UV light-irradiation.

\section{Conclusions}

The well-defined fluorescent ABA type amphiphilic triblock copolymers (PS- $b$ PNIPAM- $b$-PS) were synthesized in a controlled way via RAFT polymerization using BNTTC as RAFT agent. The copolymers have controlled molecular weights and relatively narrow molecular weight distribution (PDI < 1.2). The prepared PS- $b-$ PNIPAM- $b$-PS could self-assemble into larger micelles (several micron) by addition of water to polymer/DMF solution, with the hydrophobic PS segments at the cores of micelles and the hydrophilic PNIPAM segments as the outer shells. Furthermore, the sizes and morphologies of the formed micelles were sensitive to the irradiation of UVlight due to the fragmentation of the trithiocarbonate group in the middle of the triblock copolymer.

\section{Experimental}

\section{Materials}

The monomer, styrene (St) was washed with an aqueous solution of sodium hydroxide (5 wt \%) for three times and then with deionized water until neutralization. After being dried with anhydrous magnesium sulfate, the monomer was distilled under reduced pressure and kept in a refrigerator under $0{ }^{\circ} \mathrm{C}$ for short store. 1chloromethyl naphthalene and $\mathrm{n}-\mathrm{Bu}_{4} \mathrm{NHSO}_{4}$ were purchased from Aldrich Chemical Co. and used as received. N-Isopropylacrylamide (NIPAM, Kohjin Co., Japan, 97\%) was purified by recrystallization from a toluene/hexane mixture. 2,2'Azoisobutyronitrile (AIBN) was recrystallized from ethanol. Tetrahydrofuran was dried with 4-A molecular sieves and distilled in vacuum. Unless otherwise specified, all chemicals were purchased from Shanghai Chemical Reagents Co., China.

\section{Synthesis of S, S'-bis(1-naphthylmethyl) trithiocarbonate (BNTTC)}

A mixture of $10 \mathrm{~mL}$ of $\mathrm{CS}_{2}$ and $15 \mathrm{~mL}$ of $33 \%$ aqueous $\mathrm{NaOH}$ solution was stirred vigorously at room temperature in a $50 \mathrm{~mL}$ round-bottom flask with a magnetic stirrer. The phase transfer catalyst $\left(\mathrm{n}-\mathrm{Bu}_{4} \mathrm{NHSO}_{4}, 3 \mathrm{~mol} \%\right.$ to the 1-Chloromethyl 
naphthalene used) was then introduced. After stirring for $10 \mathrm{~min}, 2 \mathrm{~g}(11.3 \mathrm{mmol})$ of 9-chloromethyl naphthalene was added. To work up the reaction (after 12 hour), the products were washed with acetone $(3 \times 10 \mathrm{~mL})$. Then recrystallization from acetone gave a thin yellow crystal (Scheme 3), and the purity was greater than $99 \%$ determined from HPLC. Yield: $90 \%$. ${ }^{1} \mathrm{H}$ NMR $\left(\mathrm{CDCl}_{3}, \delta\right): 5.00-5.30,4 \mathrm{H}(\mathrm{s}) ; 7.38-7.48$, $2 \mathrm{H}(\mathrm{m}) ; 7.48-7.68,6 \mathrm{H}(\mathrm{m}) ; 7.75-7.94,4 \mathrm{H}(\mathrm{m}) ; 7.95-8.10,2 \mathrm{H}(\mathrm{d}) .{ }^{13} \mathrm{C} \mathrm{NMR}\left(\mathrm{CDCl}_{3}, \delta\right)$ : $223.37(\mathrm{C}=\mathrm{S}) ; 40.06\left(-\mathrm{CH}_{2}-\right)$. Elem. Anal. Calcd. \%: C, 70.73; H, 4.65; Found: C, 70.50; H, 4.78 .

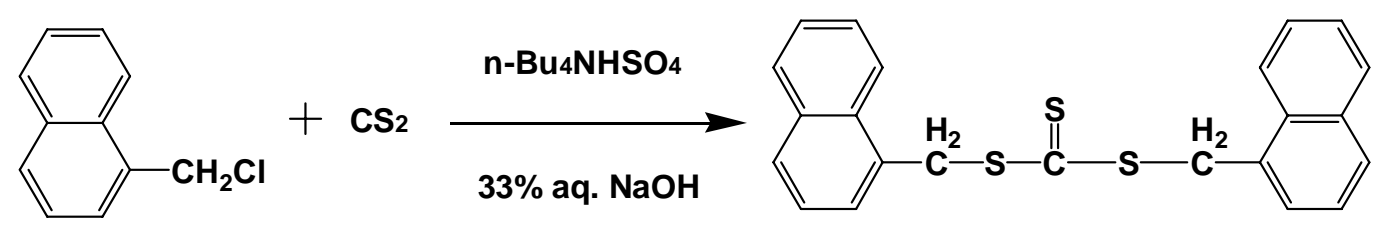

Scheme 2. Synthetic route of S,S'-bis(1-naphthylmethyl) trithiocarbonate (BNTTC)

\section{RAFT Polymerization of St Using BNTTC as RAFT Agent}

The typical procedure of RAFT polymerization of St was as follows: a stock solution containing $6 \mathrm{~mL}(52.1 \mathrm{mmol})$ of St, $406.4 \mathrm{mg}(1.0 \mathrm{mmol})$ of BNTTC and $28.5 \mathrm{mg}$ $\left(1.7 \times 10^{-1} \mathrm{mmol}\right)$ of AIBN were prepared and placed in $10 \mathrm{ml}$ ampoule. The content was purged with argon for approximately $10 \mathrm{~min}$ to eliminate the dissolved oxygen. Then the ampoules were flame sealed and placed in an oil bath held by a thermostat at $70{ }^{\circ} \mathrm{C}$ to polymerize. After a preset reaction time, each ampoule was cooled with ice water and opened. The reaction mixture was diluted with proper tetrahydrofuran (ca. $5 \mathrm{~mL}$ ) and precipitated in a large amount of methanol (ca. $500 \mathrm{~mL}$ ). The polymer was obtained by filtration and dried at room temperature in vacuum to a constant weight. The conversion of polymerization was determined gravimetrically.

\section{Synthesis of Fluorescent ABA Type Amphiphilic Triblock Copolymers PS-b-PNIPAM- $b-P S$}

Block copolymerization was performed in the same manner as the typical RAFT procedure for the polymerization of St. The reaction mixture containing $0.4 \mathrm{~g}$ (3.5 mmol) of NIPAM, $1.5 \mathrm{~mL}$ of THF, macro-RAFT agent, and AIBN ([macro-RAFT agent $]_{0}:[A I B N]_{0}=6: 1$, molar ratio) were introduced into a $5 \mathrm{~mL}$ dry ampoule. The yellow homogeneous solution was purged with argon for $10 \mathrm{~min}$. Then the ampoules were flame sealed and placed in an oil bath held by a thermostat at $70{ }^{\circ} \mathrm{C}$ to polymerize. After a preset reaction time, each ampoule was cooled with ice water and opened. The reaction mixture was diluted with proper tetrahydrofuran (ca. $2 \mathrm{~mL}$ ) and precipitated in a large amount of cold methanol (ca. $300 \mathrm{~mL}$ ). The block copolymer was obtained by filtration and dried at room temperature in vacuum to a constant weight. The conversion of polymerization was determined gravimetrically.

\section{Preparation of the Micelle Solutions}

The triblock copolymer (between $1 \mathrm{wt} \%$ to $6 \mathrm{wt} \%$ ) was dissolved in DMF, a common solvent for both PS and PNIPAM blocks, and subsequent addition of deionized water to the solution to induce aggregation of the PS blocks at room temperature $25^{\circ} \mathrm{C}$ ). After a predetermined water content ( $5.5 \mathrm{wt} \%)$ had been reached, the water addition was stopped for 1 day with vigorous stirring. After the formation of the micelles, the morphologies of aggregates were observed by TEM. 


\section{Characterization}

The molecular weights and polydispersities of the PS were determined with a Waters 1515 gel permeation chromatograph (GPC) equipped with refractive index detector, using HR1, HR3, and HR4 columns (used to measure the polymers with the molecular weights range $100-500,000 \mathrm{~g} / \mathrm{mol}$ ) calibrated with PS standard sample. THF was used as the eluent at a flow rate of $1.0 \mathrm{~mL} \mathrm{~min}{ }^{-1}$ operated at $30{ }^{\circ} \mathrm{C}$. ${ }^{1} \mathrm{H}$ NMR spectra of the polymers were recorded on an INOVA $400 \mathrm{MHz}$ nuclear magnetic resonance instrument, using $\mathrm{CDCl}_{3}$ as a solvent and tetramethyl silane as the internal standard. The fluorescence emission spectra of the polymers were obtained on an Ediburger FLS920 fluorescence spectrophotometer with THF as solvent at room temperature. The elemental analyses for $\mathrm{C}, \mathrm{H}$, and $\mathrm{N}$ were performed on a LECO-CHNS microanalyzer. The UV absorption spectra of the samples in THF were determined on a UV 240 spectrophotometer. FT-IR spectra were recorded on a Perkin-Elmer 2000 FT-IR spectrometer. The purity of products was determined on high-performance liquid chromatograph (HPLC, mode 515, Waters) with the solvent acetonitrile as the eluent at $30{ }^{\circ} \mathrm{C}$. Transmission electron microscopy (TEM) was recorded on a Tecnai G2-20 TEM at a $200 \mathrm{kV}$ accelerating voltage. The samples were prepared by mounting a drop of the micelle solution $(0.05 \mathrm{~mL})$ on a copper $\mathrm{EM}$ grid covered with a thin film of formvar. Surface tension $(\gamma)$ of $D M F / \mathrm{H}_{2} \mathrm{O}$ solutions of copolymers PS- $b$-PNIPAM- $b$-PS were measured by Du Noüy method on a JK99C automatic surface tensiometer (Shanghai Zhongchen Co., China) equipped with a platinum ring. Each sample was measured three times at $25{ }^{\circ} \mathrm{C}$, and then the average surface tension was calculated.

\section{Acknowledgements}

The financial support of this work by the National Nature Science Foundation of China (No.20874069), the Science and Technology Development Planning of Jiangsu Province (No. BK2007702 and BK2007048) and the Nature Science Key Basic Research of Jiangsu Province for Higher Education (No. 05KJA15008) are gratefully acknowledged.

\section{References}

[1] Allen C.; Maysinger D.; Eisenberg A. Colloids Surf. B 1999, 16, 3.

[2] Jones M. C.; Leroux J. C. Eur. J. Pharm. Biopharm. 1999, 48, 101.

[3] Kataoka K.; Harada A.; Nagasaki Y. Adv. Drug Delivery Rev. 2001, 47, 113.

[4] Kwon G. S. Crit. Rev. Ther. Drug Carrier Syst. 2003, 20, 357.

[5]. Monnard, P. A.; Deamer, D. W. Anat. Rec. 2002, 268, 196.

[6]. (a) Zhang, L.; Eisenberg, A.; Science 1995, 268, 1728; (b) Discher, B. M.; Won, Y. Y.; Ege, D. S.; Lee, J. C. M.; Bates, F. S.; Disher, D. E.; Hammer, D. A. Science 1999, 284, 1143.

[7] (a) Chen, Z.; Cui, H.; Hales, K.; Li, Z.; Qi, K.; Pochan, D. J.; Wooley, K. L. J .Am. Chem. Soc. 2005, 127, 8592; (b) Wooley, K. L. J. Polym. Sci., Part A: Polym. Chem. 2000, 38, 1397.

[8] Nasongkla N.; Shuai X. T.; Ai H.; Weinberg B. D.; Pink J.; Boothman D. A.; Gao J.

M. Angew. Chem. 2004, 116, 6483; Angew. Chem. Int. Ed. 2004, 43, 6323.

[9] Pan X. Y.; Mu M. F.; Hu B.; Yao P.; Jiang M. Biopolymers 2006, 81, 29.

[10] Soppimath K. S.; Tan D. C.W.; Yang Y. Y. Adv. Mater. 2005, 17, 10318.

[11] Sotiriou K.; Nannou A.; Velis G.; Pispas S. Macromolecules 2002, 35, 4106. 
[12] Yun J.; Faust R.; Szilagyi L. S.; Keki S.; Zsuga M. Macromolecules 2003, 36, 1717.

[13] (a) Nuopponen, M.; Ojala, J.; Tenhu, H. Polymer 2004, 45, 3643; (b) Zhang, W. A.; Zhou, X. C.; Li, H.; Fang, Y. E.; Zhang, G. Z. Macromolecules 2005, 38, 909

[14] Kitano, H.; Fukui, N.; Ohhori, K.; Maehara, Y.; Kokado, N.; Yoshizumi, A. J. Colloid Interface Sci. 1999, 212, 58.

[15] Ge, Z. S.; Luo, S. Z.; Liu, S. Y. J. Polym. Sci., Part A: Polym. Chem. 2006, 44, 1357.

[16] Schilli, C. M.; Zhang, M.; Rizzardo, E.; Thang, S. H.; Chong, Y. K.; Edwards, K.; Karlsson, G.; Mueller, A. H. E. Macromolecules 2004, 37, 7861.

[17] You, Y. Z.; Hong, C. Y.; Wang, W. P.; Lu, W. Q.; Pan, C. Y. Macromolecules 2004, 37, 9761.

[18] Zhang, W. Q.; Jiang, X. W.; He, Z. P.; Xiong, D. A.; Zheng, P. W.; An, Y. L.; Shi, L. Q. Polymer 2006, 47, 8203.

[19] (a) Hillmer, M. A.; Bates, F. S.; Macromolecules 1996, 29, 6994; (b) Busse, K.; Kressler, J.; Eck, D. V.; Horing, S. Macromolecules 2002, 35, 178.

[20] Ma, Q.; Wooley, K. L. J. Polym. Sci., Part A: Polym. Chem. 2000, 38, 4805.

[21] Patrickios, C. S.; Forder, C.; Armes, S. P.; Billingham, N. C. J. Polym. Sci., Part A: Polym. Chem. 1996, 34, 1529.

[22] Zhang, X.; Matyjazewski, K. Macromolecules 1999, 32, 1763.

[23] Forster, S.; Antonietti, M. Adv. Mater. 1998, 10, 195.

[24] Moad, G.; Rizzardo, E.; Thang, S. H. Aust. J. Chem. 2006, 59, 669.

[25] Matyjaszewski, K.; Mueller, A. H. E. Prog. Polym. Sci. 2006, 31, 1039.

[26] Matyjaszewski, K. Symposium Series. 2003, no. 688.

[27] Jie, X.; Wei, Z.; Nian, C. Z.; Jian, Z.; Zhen, P. C.; Xiu, L. Z. e-Polymers 2008, no. 024 .

[28] (a) Liu, B.; Perrier, S. J. Polym. Sci., Part A: Polym. Chem. 2005, 43, 3643; (b) Nguyen T. L. U.; Eagles, K.; Davis, T. P.; Barner-Kowollik, C.; Stenzel, M. H. J. Polym. Sci., Part A: Polym. Chem. 2006, 44, 4372; (c) Stenzel, M. H.; BarnerKowollik, C.; Davis, T. P. J. Polym. Sci., Part A: Polym. Chem. 2006, 44, 2363.

[29] Schilli, C.; Lanzendoerfer, M. G.; Mueller, A. H. E. Macromolecules 2002, 35, 6819.

[30] Ganachaud, F.; Monteiro, M. J.; Gilbert, R. G.; Dourges, M. A.; Thang, S. H.; Rizzardo, E. Macromolecules 2000, 33, 6738.

[31] Li, P. Y.; Jian, Z.; Zhen, P. C.; Zheng, B. Z.; Wei, Z; Xiu, L. Z. e-Polymers 2007, no. 092

[32]. Li, W. Z.; Yan, H. Z.; Yong, M. C. Eur. Polym. J. 2006, 422398.

[33] Jun, L.; Chun, Y. H.; Cai, Y. P. Polymer 2004, 45, 4413.

[34] John, F. Q.; Barner, L.; Christopher, B. Macromolecules 2002, 35, 7620.

[35] Kazunori, T.; Masaya, M.; Asao, N.; Takeo, K. Tetrahedron Lett.. 2006, 47,1241.

[36] Wang, S. M.; Cheng, Z. P.; Zhu, J.; Zhang, Z. B.; Zhu, X. L. J. Polym. Sci., Part A: Polym. Chem. 2007, 45, 5318.

[37] Ye, Z. Y.; Chun, Y. H.; Ru, K. B. Macromol Chem Phys. 2002, 203, 477.

[38] Gao, Z.; Varshney, S. K.; Wong, S.; Eisenberg, A. Macromolecules 1994, 27, 7923.

[39] Zhang, L.; Barlow, R. J.; Eisenberg, A. Macromolecules 1995, 28, 6055.

[40] Zhang, L.; Eisenberg, A. Macromolecules 1999, 32, 2239.

[41] Zhang, L.; Eisenberg, A. Polym. Adv. Technol. 1998, 9, 677.

[42] Zhang, L.; Eisenberg, A. Macromol. Symp. 1997, 113, 221. 